\title{
Facile Detection of Vitamin B12 with Copper Oxide Nanocrystal Graphenic Composite Electrode
}

\author{
Chao Tian ${ }^{1}$, Na Zhao ${ }^{2}$, Xinyue Jiang ${ }^{1}$, Duanji Wan ${ }^{1}$ and Yuqun Xie ${ }^{3, *}$ \\ 1 School of Civil Engineering Architecture and Environment, Hubei University of Technology, \\ Wuhan 430068, China; chaotian@hbut.edu.cn (C.T.); xinyuejiang@hbut.edu.cn (X.J.); \\ duanjiwan@163.com (D.W.) \\ 2 School of Life Sciences, Hubei Key Laboratory of Genetic Regulation and Integrative Biology, Central China \\ Normal University, Wuhan 430068, China; zhaona@mails.ccnu.edu.cn \\ 3 School of Bioengineering and Food Science, Hubei University of Technology, Wuhan 430068, China \\ * Correspondence: yuqunxie@hbut.edu.cn
}

check for updates

Citation: Tian, C.; Zhao, N.; Jiang, X.; Wan, D.; Xie, Y. Facile Detection of Vitamin B12 with Copper Oxide Nanocrystal Graphenic Composite Electrode. Water 2021, 13, 1790. https: / doi.org/10.3390/w13131790

Received: 24 May 2021

Accepted: 26 June 2021

Published: 28 June 2021

Publisher's Note: MDPI stays neutral with regard to jurisdictional claims in published maps and institutional affiliations.

Copyright: (c) 2021 by the authors. Licensee MDPI, Basel, Switzerland. This article is an open access article distributed under the terms and conditions of the Creative Commons Attribution (CC BY) license (https:// creativecommons.org/licenses/by/ $4.0 /)$

\begin{abstract}
Vitamin B12 (VB12) is applied as the cofactors in various important enzymatic reactions and is involved in gene expression regulation mediated by B12-riboswitch and the VB12-dependent photoreceptor. Rapid detection VB12 concertation in a given environment may provide insights in the evaluation of micronutrient levels and the physiological and ecological performances of organisms under the relevant condition. This study demonstrating an amperometric approach to quantify the VB12 in biological samples without complicated sample pretreatment. The electrochemical oxidation step was conducted with a plain graphenic electrode to convert all nitrogen groups within the VB12 molecules to $\mathrm{NO}_{3}{ }^{-}$at $1.3 \mathrm{~V}$ vs. $\mathrm{Ag} / \mathrm{AgCl}$ for $15 \mathrm{~min}$. VB12 was quantified stoichiometrically according to the oxidized nitrate anions, which were reduced with copper oxide nanocrystal decorated graphenic electrode. Cathodic polarization was conducted with a graphite rod electrode before nitrate reduction to eliminate the potential interferences. Under optimized experimental conditions, the presented approach gave a wide detection linear range of $0.15-7378 \mathrm{nmol} \mathrm{L}^{-1}$ and the detection limit was $0.59 \mathrm{nmol} \mathrm{L}^{-1}$. The results for biological samples were comparable to those of the HPLC method. These results indicated that successively combined anodic and cathodic polarization enhanced the detection sensitivity and efficiency of the electrode towards VB12. The proposed electrode shows potential in terms of efficiency, reliability and accuracy for rapid determination of VB12 in biological samples.
\end{abstract}

Keywords: copper oxide; electrochemical detection; GUITAR; electrochemical oxidation; vitamin B12

\section{Introduction}

Vitamin B12 (VB12), one of the most complex metabolites, is an essential micronutrient for many organisms. VB12 is composed of a cobalt-containing corrin ring, a nucleotide loop, and the upper and lower ligands to cobalt ion. The upper ligand can be deoxyadenosine in adenosylcobalamin (coenzyme B12), the methyl group in methylcobalamin, or the cyano group in cyanocobalamin, and the lower ligands normally are 5,6-dimethylbenzimidazole (DMB) [1]. These VB12-derivatives are used as the cofactors in various important enzymatic reactions such as cobalamin-dependent methyl transfer, isomerization and reduction reactions [2]. VB12 can also be involved in gene expression regulation mediated by B12riboswitch and VB12-dependent photoreceptors [3,4]. These properties allow VB12 to play a fundamental role in both the central metabolism of organisms and the functions of ecological systems. Although many organisms require VB12, they may not be able to biosynthesize VB12 from scratch [5]. These VB12 auxotrophs have to obtain VB12 thought scavenging it from the environment or exchanging it with other VB12 producers. Rapidly determining the VB12 concertation in a given environment has the potential to provide insights in the evaluation of micronutrient levels and the physiological and ecological performances of 
organisms under this condition. Therefore, it is quite essential to develop simple, selective, and reliable approaches for the determination of VB12 in biological samples.

Up to now, many analytical techniques have been extensively investigated for VB12 determination [6-12], e.g., chemiluminescence, ultraviolet-visible spectrophotometry, highperformance liquid chromatography (HPLC), capillary electrophoresis (CE), and flame atomic absorption spectrometry (FAAS). These techniques possess some unique advantages. However, some drawbacks exist, such as expensive instruments, a lack of sensitivity and specificity, requiring centralized laboratories, and complicated sample preparation [6-12]. These methods are unable to meet the requirement for effective monitoring of vitamin B12 in biological samples. The electrochemical approach has drawn intensive attention due to the operation convenience, superior sensitivity, and low budget. The electrochemical detection of VB12, based on diverse sensing electrodes have been applied by researchers [13-20]. Various electrodes, for instance, a carbon paste electrode modified with trans-1, 2-dibromocyclohexane, poly(thionine) modified glassy carbon, single-walled carbon nanotube-chitosan-modified disposable pencil graphite electrode, gold, mercury, plated bismuth-film electrode, graphite screen-printed electrode, and the boron-doped diamond electrode has been employed for the quantification analysis of VB12. They are all focused on detecting the variation of the valence state of cobalt elements within the VB12. Limited reports have been addressed on monitoring the nitrogen element in VB12 [13-20]. A novel perspective to quantify the VB12 concentration in the aqueous sample indirectly by oxidizing the nitrogen-containing group within VB12 to nitrate through hydroxyl radicals, which were generated on the GUITAR (graphenic material synthesized by the University of Idaho thermolyzed asphalt reaction) electrode, then nitrate was detected by electrochemical reduction with the copper oxide modified GUITAR electrode. Copper oxide was reported to be a catalytic material for nitrate reduction, and it showed excellent activity for the electroreduction of nitrate to ammonia during the reaction [21]. The proposed reaction processes are as follows [22,23].

$$
\begin{aligned}
& \mathrm{NO}_{3}{ }^{-}{ }_{\text {(aq) }} \rightarrow \mathrm{NO}_{3}{ }^{-} \text {(ads) } \quad E^{0}=-0.6 \mathrm{~V} \text { vs. } \mathrm{Hg} / \mathrm{HgO} \\
& \mathrm{NO}_{3}{ }^{-}{ }_{\text {(ads) }}+\mathrm{H}_{2} \mathrm{O}+2 \mathrm{e}^{-} \rightarrow \mathrm{NO}_{2}{ }^{-}{ }_{\text {(ads) }}+2 \mathrm{OH}^{-} \quad E^{0}=-0.9 \mathrm{~V} \text { vs. } \mathrm{Hg} / \mathrm{HgO} \\
& \mathrm{NO}_{2}{ }^{-} \text {(ads) }+4 \mathrm{H}_{2} \mathrm{O}+4 \mathrm{e}^{-} \rightarrow \mathrm{NH}_{2} \mathrm{OH}+5 \mathrm{OH}^{-} \quad E^{0}=-1.1 \mathrm{~V} \text { vs. } \mathrm{Hg} / \mathrm{HgO} \\
& \left.2 \mathrm{NO}_{2}{ }^{-}{ }^{-} \text {ads }\right)+4 \mathrm{H}_{2} \mathrm{O}+6 \mathrm{e}^{-} \rightarrow \mathrm{N}_{2}+8 \mathrm{OH}^{-} \quad E^{0}=-1.23 \mathrm{~V} \text { vs. SCE } \\
& \mathrm{NO}_{2}{ }^{-}{ }_{\text {(ads) }}+6 \mathrm{H}_{2} \mathrm{O}+6 \mathrm{e}^{-} \rightarrow \mathrm{NH}_{4}{ }^{+}{ }_{\text {(ads) }}+8 \mathrm{OH}^{-} \quad E^{0}=-1.3 \mathrm{~V} \text { vs. } \mathrm{Hg} / \mathrm{HgO}
\end{aligned}
$$

Among the above-mentioned reactions, the nitration step is extremely significant. Previous studies have described the hydroxyl radicals $(\bullet \mathrm{OH})$ oxidation capability to some organic matter, which is widely applied in environmental chemistry to decompose organic pollutants in the wastewater [24,25]. A series of studies have shown that the $\bullet \mathrm{OH}$ was produced electrochemically through anodic polarization oxidation of water with anodic stable electrodes [26]. GUITAR is regarded as well-established anodic stable electrode material [27]. Particularly, GUITAR has a combination of fast electron transfer with redox species and extremely high anodic corrosion potentials. The anodic limit of GUITAR is 2.7 V vs. SHE and exhibits anodic stability surpass boron-doped diamond electrodes [27]. Based on these advantages of the GUITAR electrode, it was utilized for the VB12 oxidation.

In this predetermined study, VB12 was quantified stoichiometrically according to the oxidized nitrate anions, which were reduced to ammonium ions with a copper oxide nanocrystal decorated GUITAR electrode. Cathodic polarization was conducted with a graphite rod electrode before the oxidation reduction to eliminate the potential interferences. The electrochemical oxidation step was carried out with a GUITAR electrode to convert all nitrogen groups within the $\mathrm{VB} 12$ molecules to $\mathrm{NO}_{3}{ }^{-}$at $1.3 \mathrm{~V}$ vs. $\mathrm{Ag} / \mathrm{AgCl}$ for $15 \mathrm{~min}$, subsequently a copper oxide nanocrystal modified GUITAR electrode was utilized to a 
reduction reaction at $-1.36 \mathrm{~V}$ vs. $\mathrm{Ag} / \mathrm{AgCl}$ for $1 \mathrm{~min}$. Figure 1 schematically represents the basic strategies of demonstrated electrochemical sensors for VB12 determination.

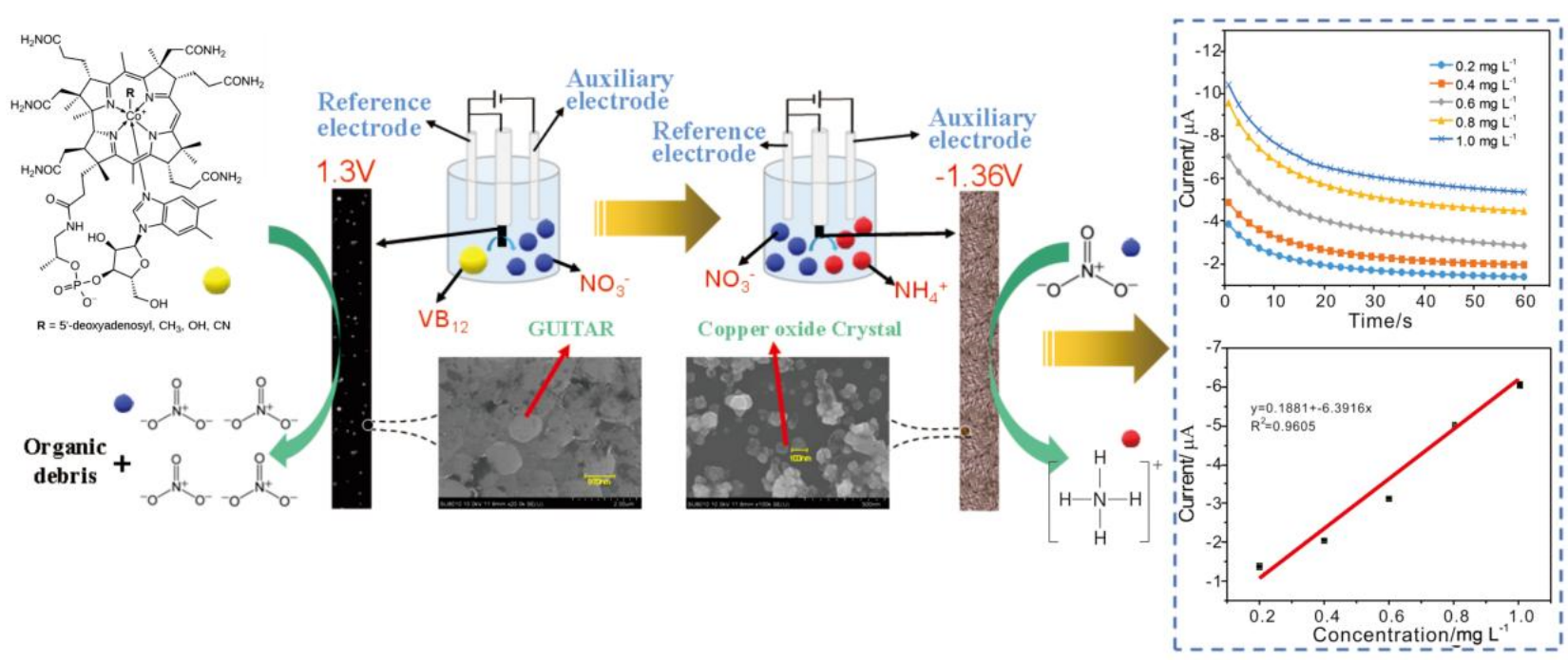

Figure 1. Schematic diagram of the proposed electrochemical detection of VB12.

\section{Experimental}

\subsection{Reagents and Chemicals}

VB12 (purity, 98\%) was purchased from (Bioforxx, Germany). Potassium nitrate was acquired from the Tianjin Fuchen Chemical Reagent Factory (Tianjin, China). Potassium ferricyanide, ammonium sulfate, sodium sulfate, sodium chloride, and copper chloride were obtained from Shanghai Sinopharm Chemical Reagent Co., Ltd. (Shanghai, China). All chemical reagents are consumed directly without any purification steps and all used solutions were prepared with deionized water (resistivity higher than $16 \mathrm{M} \Omega \mathrm{cm}$ ). Petroleum waste was obtained from Hubei Jingshi Waterproof Material Engineering Co., Ltd. (Wuhan, China). The C18 column was obtained from CNW Technologies (Shanghai, China). The biological sample was obtained from the Hubei Key Laboratory of Genetic Regulation and Integrative Biology (Wuhan, China).

\subsection{Apparatus}

All the electrochemical tests were carried out on an electrochemical workstation (CorrTest, Wuhan, China) with a three-electrode electrolytic cell, in which the prepared electrode, $\mathrm{Ag} / \mathrm{AgCl}$ electrode, and platinum wire were applied as a working electrode, reference electrode, and counter electrode, respectively. XB220A electronic analytical balance (Precisa), DHG-9053A electric constant temperature air dryer (Kunshan, China), and KQ5200DE CNC ultrasonic cleaner (Shanghai, China) was also utilized for the entire experiment. A high-performance liquid chromatography (HPLC) (Palo Alto, Santa Clara, CA, USA) was applied for the quantification analysis of VB12. UV2550 UV spectrophotometers (Kyoto, Japan) were used for absorbance analysis.

\subsection{Preparation of the GUITAR Electrode}

The graphenic material synthesized by the University of Idaho thermolyzed asphalt reaction (GUITAR) film was loaded on the silicon wafer substrates functionalized by hydrophobic organic groups in an aqueous solution according to a previous study [28].

\subsection{Preparation of the Copper Oxide-Modified GUITAR Electrode}

Copper oxide-modified GUITAR electrode was prepared by cathode polarization. A three-electrode system was used for electrode modification, with the GUITAR electrode as the working electrode, the $\mathrm{Ag} / \mathrm{AgCl}$ electrode as the reference electrode, and the platinum 
wire electrode as the auxiliary electrode. In $5 \mathrm{mM} \mathrm{CuCl}_{2}$ solution (containing $0.5 \mathrm{M} \mathrm{NaCl}$ as the electrolyte), the cathode was polarized at $-0.5 \mathrm{~V} \mathrm{vs.} \mathrm{Ag} / \mathrm{AgCl}$ for $5 \mathrm{~min}$ [29].

Before each measurement, the working electrode was pretreated with a cathode polarization of $-1 \mathrm{~V}$ vs. $\mathrm{Ag} / \mathrm{AgCl}$ for $3 \mathrm{~min}$ in $0.5 \mathrm{M}$ electrolyte solution.

\subsection{Electrochemical Measurements}

Electrochemical steady-state polarization measurements were taken with a threeelectrode system. The electrochemical oxidation step was carried out with a GUITAR electrode as the working electrode, a copper oxide nanocrystal modified GUITAR electrode as the working electrode was utilized to a reduction reaction, the $\mathrm{Ag} / \mathrm{AgCl}$ electrode was used as the reference electrode, and the platinum wire electrode as the auxiliary electrode. All the testing solutions contained $0.5 \mathrm{M} \mathrm{Na}_{2} \mathrm{SO}_{4}$ as the supporting electrolyte. All electrochemical measurements were performed in neutral $(\mathrm{pH}=7)$ solutions.

\subsection{Preparation of Standard Solution}

The stock solution was made by dissolving the VB12 standard in $0.5 \mathrm{M} \mathrm{Na}_{2} \mathrm{SO}_{4}$. A serial dilution was followed up to obtain $0.2-1 \mu \mathrm{g} \mathrm{L}^{-1}, 2-10 \mu \mathrm{g} \mathrm{L}^{-1}, 0.02-0.10 \mathrm{mg} \mathrm{L}^{-1}$, $0.2-1.0 \mathrm{mg} \mathrm{L}^{-1}$, and $2-10 \mathrm{mg} \mathrm{L}^{-1} \mathrm{VB1} 12$ solutions containing $0.5 \mathrm{M} \mathrm{Na}_{2} \mathrm{SO}_{4}$ as the electrolyte.

\subsection{Interference Elimination of the Biological Sample}

Cathodic polarization was used to eliminate the metal ion interference in the real biological sample. Graphite carbon rod, platinum wire, and $\mathrm{Ag} / \mathrm{AgCl}$ were applied as the working electrode, auxiliary electrode, and reference electrode, respectively, and the polarized potential was $-0.5 \mathrm{~V}$ vs. $\mathrm{Ag} / \mathrm{AgCl}$.

\subsection{Standard Addition Method}

Concentrated VB12 solution was spiked into real biological samples dropwise to perform the standard addition quantification. The final serial concentrations of VB12 in liquor were $0.5 \mathrm{mg} \mathrm{L}^{-1}$ and $5 \mathrm{mg} \mathrm{L}^{-1}$ with a total volume of $10 \mathrm{~mL}$.

\subsection{Method Validation with HPLC}

First, $10 \mathrm{~mL}$ of the VB12 sample was subjected to solid-phase extraction using a C18 column, and then the $\mathrm{C} 18$ column was rinsed by $15 \mathrm{~mL}$ of $50 \%$ methanol [30]. The adsorbent was cleaned with $20 \mathrm{~mL}$ of ultrapure water, the absorbed compounds were desorbed with $20 \mathrm{~mL}$ of methanol, and then concentrated by purging with nitrogen. The volume of the extract was adjusted to $10 \mathrm{~mL}$ for HPLC and amperometric analysis. This prevents proteins in the biological sample from interfering with the experimental results. All samples were repeated three times for cyclic tests. The external standard method was used for the establishment of a calibration curve and VB12 determination in the biological sample.

\section{Results and Discussion}

\subsection{Characterization of Electrodes}

The morphologies of GUITAR and the copper oxide nanocrystal modified GUITAR electrode were characterized by a scanning electron microscope (SEM). As observed in Figure 2a, the GUITAR films prepared by the optimal amounts of petroleum wastes show irregular grain morphology with an average grain size of about $970 \mathrm{~nm}$. GUITAR is considered as an ideal substrate for copper oxide crystals decorating owing to its excellent physicochemical properties, such as excellent mechanical properties, superior thermal conductivity, and large surface area [31-33]. The increased surface areas of the layered GUITAR structure may be beneficial to the deposition of copper oxide nanoparticles [34]. After electrodeposition, the copper oxide particles uniformly covered the GUITAR surface with an average $100 \mathrm{~nm}$ in particle size (Figure $2 \mathrm{~b}$ ). 

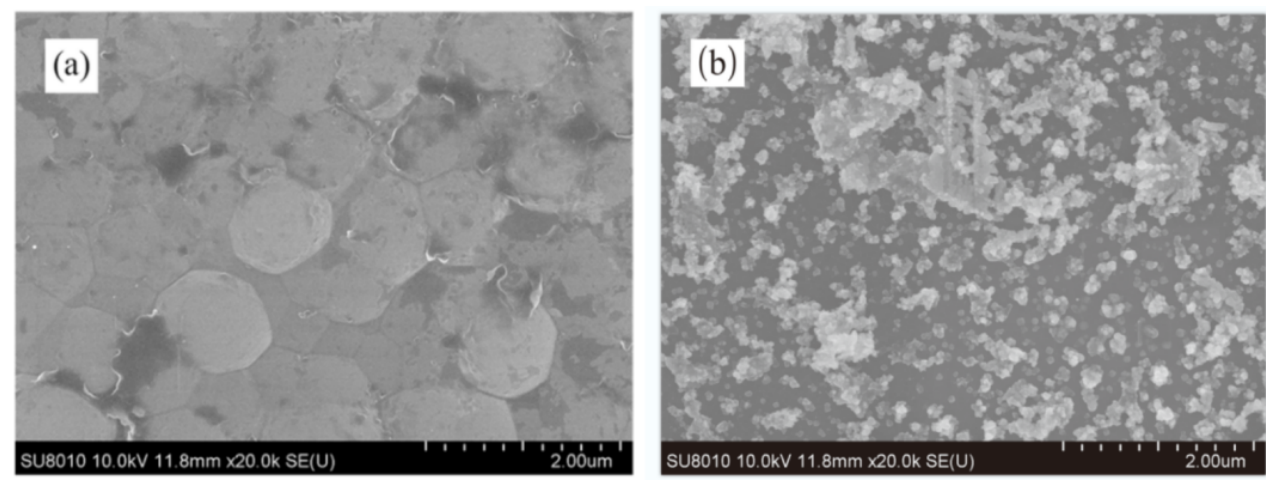

Figure 2. SEM images of (a) GUITAR and (b) the copper oxide-modified GUITAR electrode.

\subsection{Electrochemical Oxidation of VB12}

In 1960, Bernhauer [35] proposed that the solution system, which was adjusted to alkaline by amide hydrolysis, could break the VB12 cobalt bond and side chain. Davies et al. [36] found that oxidation takes place at the side chains of nitrogen-containing organic attachments. Sante-Lhoutellier et al. [37] demonstrated that with $-\mathrm{NH}$ and $-\mathrm{NH}_{2}$ on their side chains, they are extremely sensitive to hydroxyl radicals and these groups are easily oxidized. The $\bullet \mathrm{OH}$ can be produced on the GUITAR electrode through the electrochemical oxidation of water and subsequent oxidation of hydroxyl ions [38]. VB12 was electrochemically oxidized to nitrate directly and indirectly with the assistance of $\bullet \mathrm{OH}$. Therefore, the electrochemical oxidation pathway of VB12 on the GUITAR electrode was speculated in Figure 3. To verify this speculation, we compared the absorption spectra of VB12, oxidized VB12, and potassium nitrate using a UV spectrophotometer. As observed (Figure S1), VB12 finally was electrochemically converted to $\mathrm{NO}_{3}{ }^{-}$and organic residues with the assistance of $\bullet \mathrm{OH}$.

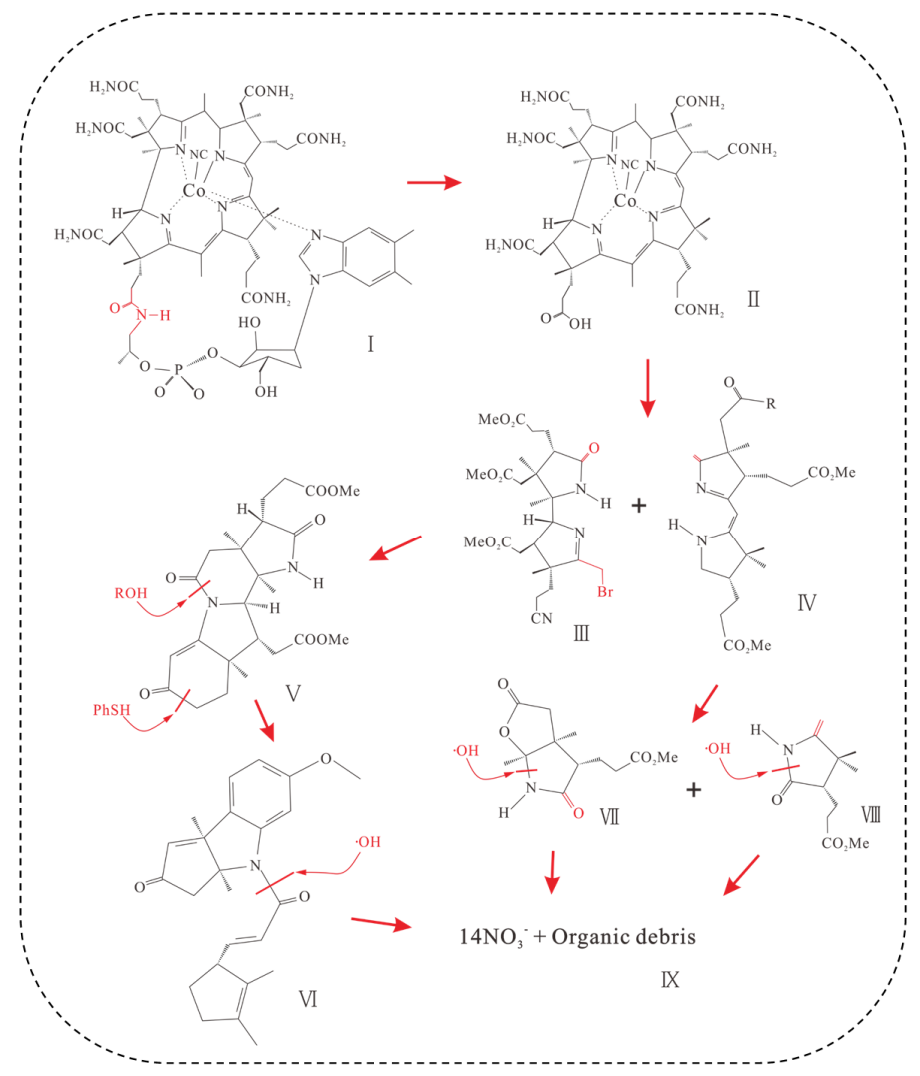

Figure 3. The electrochemical oxidation pathway of VB12. 
The electrochemical oxidation time is a key factor influencing the oxidation efficiency of VB12. Hence the impacts of oxidation time on oxidation efficiency were investigated in Figure 4a. It was observed in Figure 4a that the reduction current of $1 \mathrm{mg} \mathrm{L}^{-1} \mathrm{VB12}$ with different oxidation times $(6,9,12,15,18$, and $21 \mathrm{~min})$ were $-0.13,-17.84,-30.21,-31.24$, -31.21 , and $-31.09 \mu \mathrm{A}$, respectively. Figure S2 exhibited that the oxidation efficiency of VB12 was enhanced from 56.3 to $96.50 \%$ with increasing time from 6 to $15 \mathrm{~min}$ and remained approximately stable after $15 \mathrm{~min}$. Therefore, $15 \mathrm{~min}$ was chosen as the optimum oxidation time. Figure $4 \mathrm{~b}$ shows the absorption spectra of different concentrations of oxidized VB12, showing a clear concentration gradient at 210-250 nm, where it represents that VB12 oxidized to nitrate.
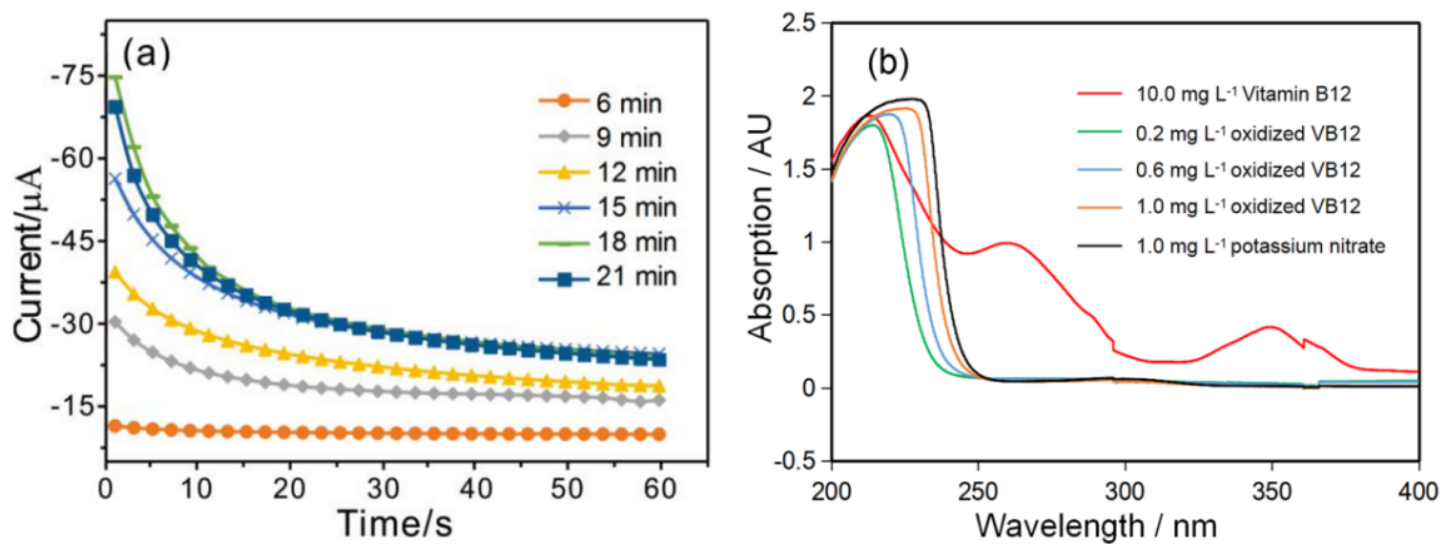

Figure 4. Effects of time on (a) current values; (b) absorption spectra of VB12, oxidized VB12, and potassium nitrate.

\subsection{The Establishment of Calibration Curves}

At first, we recorded the linear sweep voltammetry (LSV) of nitrate ions at the copper oxide modified GUITAR electrode at a scan rate of $100 \mathrm{mV} \mathrm{s}^{-1}$ to optimize the reduction potential and reproducibility of results. As can be seen in Figure 5, a reduction peak occurs at $-1.36 \mathrm{~V}$, which was attributed to a reduction reaction.
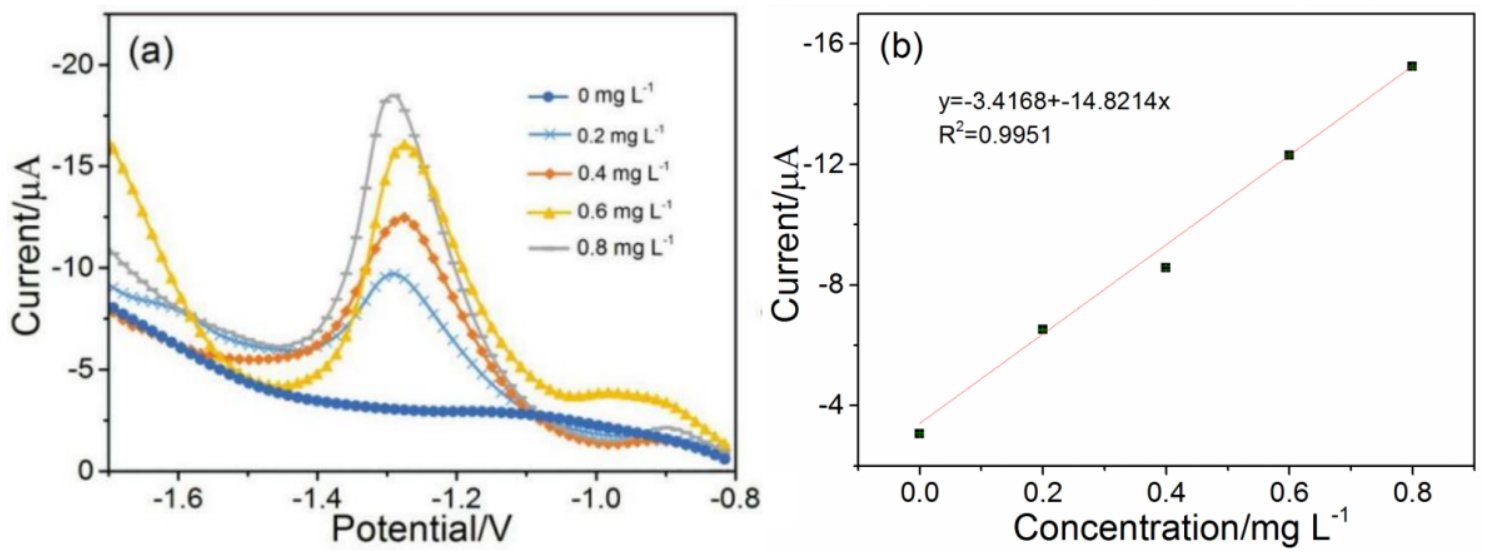

Figure 5. (a) LSV response towards different concentrations of $\mathrm{NO}_{3}^{-}\left(0-0.8 \mathrm{mg} \mathrm{L}^{-1}\right)$ and (b) the corresponding calibration curve.

Therefore, we used $-1.36 \mathrm{~V}$ as the applied potential to determine VB12 with cathodic polarization. I- $t$ curves of different VB12 concentrations in the range between 0.2 and $10 \mathrm{mg} \mathrm{L}^{-1}$ under optimal oxidation time were exhibited in Figure S3. As observed in Figure S3(a,c,e,g,i) the cathodic current of various VB12 concentrations increased at the beginning and then almost maintained stability with the increment of time. Figure $S 3(b, d, f, h, j)$ showed that the current value was directly proportional to the concentration of VB12. The stability of the modified electrodes was also recorded with a maximum deviation of $1.9 \%$. 
A linear relationship between VB12 concentrations and current values was established. The LOD (limit of detection) was estimated to be $0.59 \mathrm{nmol} \mathrm{L}^{-1}$ according to the formula $(\mathrm{LOD}=3 \mathrm{SD} / \mathrm{S})$ in the concentration range, in which $\mathrm{SD}$ is the relative standard deviation of a blank solution and $S$ is the slope of calibration plot [39], which is lower than that in the previous studies (Table 1), the copper oxide-modified GUITAR electrode in the present work shows improved detection limits.

Table 1. Performance of some electrochemical VB12 sensors.

\begin{tabular}{|c|c|c|c|c|}
\hline Electrode & Sample Source & LOD & $\begin{array}{c}\text { Detection } \\
\text { Element }\end{array}$ & Reference \\
\hline $\mathrm{GCE}(\mathrm{ea}) / \mathrm{PTH}^{\mathrm{a}}$ & Injection sample & $2 \mathrm{nmol} \mathrm{L}^{-1}$ & Cobalt & [13] \\
\hline $\mathrm{BiFE}^{\mathrm{b}}$ & Pharmaceutical & $33.1 \mathrm{nmol} \mathrm{L}^{-1}$ & Cobalt & [14] \\
\hline Au/PPy/FMNPs@TD ${ }^{c}$ & Food samples & $0.62 \mathrm{nmol} \mathrm{L}^{-1}$ & Cobalt & [15] \\
\hline SWCNT-PGE ${ }^{\mathrm{d}}$ & Pharmaceutical & $0.89 \mathrm{nmol} \mathrm{L}^{-1}$ & Cobalt & [16] \\
\hline $\mathrm{MMA} / \mathrm{SAM} / \mathrm{Au}^{\mathrm{e}}$ & Pharmaceutical & $1.0 \mathrm{nmol} \mathrm{L}^{-1}$ & Cobalt & [17] \\
\hline DBCH-CPE ${ }^{f}$ & Pharmaceutical & $0.85 \mathrm{nmol} \mathrm{L}^{-1}$ & Cobalt & [18] \\
\hline PNT-PGE $\mathrm{g}$ & Pharmaceutical & $93 \mathrm{nmol} \mathrm{L}^{-1}$ & Cobalt & [19] \\
\hline $\begin{array}{l}\text { Boron-doped diamond } \\
\text { electrode }\end{array}$ & Toothpaste & $86 \mathrm{nmol} \mathrm{L}^{-1}$ & Cobalt & [20] \\
\hline $\begin{array}{l}\text { Copper oxide-modified } \\
\text { GUITAR electrode }\end{array}$ & $\begin{array}{l}\text { Microbial } \\
\text { sample }\end{array}$ & $0.59 \mathrm{nmol} \mathrm{L}^{-1}$ & Nitrogen & This work \\
\hline
\end{tabular}

a Poly(thionine) modified glassy carbon electrode. ${ }^{b}$, Bismuth-film electrode. ${ }^{c}$, Gold/polypyrrole/ferromagnetic nanoparticles/triazine dendrimer electrode. d, Single walled carbon nanotube-chitosan modified disposable pencil graphite electrode. ${ }^{\mathrm{e}}$, Thin self-assembled monolayer of mercaptoacetic acid on a gold electrode. f, Trans-1,2-dibromocyclohexane modified carbon paste electrode. ${ }^{\mathrm{g}}$, Peptide nanotube pencil graphite electrode.

\subsection{Interference Study}

Trace amounts of metal ions were indispensable for the growth and reproduction of organisms. Yet the interfering substances such as $\mathrm{K}^{+}, \mathrm{Na}^{+}, \mathrm{Mg}^{2+}$, and $\mathrm{Ca}^{2+}$ influence considerably to quantification of VB12 in real samples, because of the similar hydrophobic features of copper oxide nanoparticles and the metal ions [40]. Figure 6 shows that the failure to remove metal ions generates a detection interference signal. The detection interference can be ascribed to the faulty signals caused by the metal ions reduction on the working electrode surface. Given this limitation, we conducted the cathodic polarization on the graphite rod electrode at $-0.5 \mathrm{~V}$ to eliminate the interference of metal ions before steady-state polarization measurements. Figure S4 showed that the removal ratio of the metal ion increased rapidly with the increase of time. The removal ratio reached $99.3 \%$ when the polarization time was $5 \mathrm{~min}$. Afterward, the removal ratio remained almost unchanged. Considering the high energy consumption at a prolonged time, the optimal polarization time was $5 \mathrm{~min}$.

\subsection{Quantification of VB12 in Biological Samples}

Standard addition was applied to determine VB12 in biological samples in order to avoid the matrix effect. We used two bacterial strains, Sinorhizobium meliloti 1021 and its $c o b D^{-}$mutant under normal and high temperature conditions, to test the performance of our method. These two strains are the wild type and VB12-deficient mutant respectively. Firstly, we performed cathodic polarization measurements under optimal polarization time to eliminate interference of metal ions and subsequent electrochemical oxidation reaction. Then the steady-state polarization measurements were carried out according to Section 2.5. The measured results of three parallel trials after the addition of VB12 with accurate concentration are shown in Table 2. The recovery values were in the range of $98.62-106 \%$, meaning that the developed sensor owns a high accuracy and it is applied in the detection of VB12 in real samples. Moreover, the stability of the modified electrodes was also recorded with a maximum deviation of $2.3 \%$. Table 3 listed the comparison of an electrochemical method in this work and HPLC for VB12 determination in four biological 
samples. As can be seen that this proposed electrochemical method achieved satisfying analytical performance as compared to HPLC. The results indicated the presented approach efficiently detected and compared the production of VB12 in the microorganism.

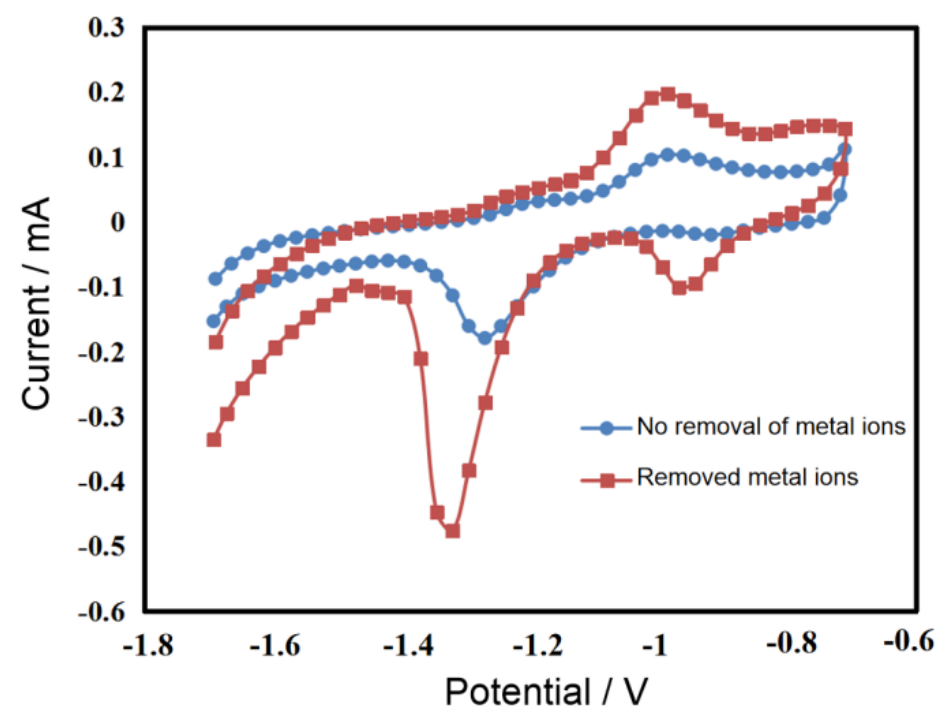

Figure 6. Comparison of the electrochemical signal without metal ion removal and with metal ion removal.

Table 2. Results for the determination of VB12 in real samples.

\begin{tabular}{ccccc}
\hline Sample & Added/nM & Found/nM & Recovery, $\%$ & $\begin{array}{c}\text { RSD, } \% \\
\mathbf{N}=\mathbf{3}\end{array}$ \\
\hline 1021 cell N & 105.00 & 107.72 & 102.59 & 2.3 \\
cobD cell N & 5.50 & 5.83 & 106.00 & 2.1 \\
1021 cell H & 60.00 & 59.17 & 98.62 & 1.7 \\
cobD cell H & 3.50 & 3.54 & 101.14 & 2.0 \\
\hline
\end{tabular}

Table 3. The comparison of this work and HPLC method for VB12 determination.

\begin{tabular}{cccc}
\hline Sample & This Work/nM & HPLC/nM & Error/nM \\
\hline 1021 cell N & 107.72 & 106.47 & +1.25 \\
cobD cell N & 5.83 & 5.24 & +0.59 \\
1021 cell H & 59.17 & 57.77 & +1.40 \\
cobD cell H & 3.54 & 3.17 & +0.37 \\
\hline
\end{tabular}

\section{Conclusions}

In summary, an electrochemical sensor-based copper oxide modified GUITAR electrode for the quantitative detection of VB12 in biological samples was successfully fabricated. The synthesized electrode materials were assessed by SEM and electrochemical techniques. The influences of time on oxidation efficiency of VB12 and removal ratio of metal ions were investigated systematically. The designed sensor offered a wide linear response range of $0.15-7378 \mathrm{nmol} \mathrm{L}^{-1}$. The lowest LOD was calculated to be $0.59 \mathrm{nmol} \mathrm{L}^{-1}$. The synergistic effects of copper oxide nanoparticles and the GUITAR electrode contributed greatly to the superior performance towards VB12 sensing. Additionally, applying cathodic polarization measurements to eliminate the interference of metal ions is demonstrated to be feasible for the determination of VB12. This proposed method exhibited satisfying detection performance as compared to HPLC. We believe that this method for VB12 determination offered a facile approach to evaluate the micronutrient levels of biological samples, it is a potentially powerful tool for VB12-involved basic biological and environmental research. 
Supplementary Materials: The following are available online at https:/ / www.mdpi.com/article/10 .3390 /w13131790/s1, Figure S1: Absorption spectra of VB12, oxidized VB12 and potassium nitrate, Figure S2: Oxidation efficiency of VB12, Figure S3: I-t curves of VB12 with different concentrations in the range of $0.2-1 \mu \mathrm{g} \mathrm{L}^{-1}$ (a), 2-10 $\mu \mathrm{g} \mathrm{L}^{-1}$ (c), 0.02-0.10 $\mathrm{mg} \mathrm{L}^{-1}$ (e), 0.2-1.0 $\mathrm{mg} \mathrm{L}^{-1}$ (g), 2-10 $\mathrm{mg} \mathrm{L}^{-1}$ (i) at $-1.36 \mathrm{~V}$ and $(b, d, f, h$, and $j)$ corresponding calibration plots, Figure S4: Effect of polarization time on the removal ratio of metal ions at $-0.5 \mathrm{~V}$.

Author Contributions: Conceptualization, Y.X.; methodology, Y.X. and C.T.; validation, C.T. and X.J.; resources, N.Z. and Y.X.; data curation, C.T. and X.J.; writing-original draft preparation, C.T., N.Z. and X.J.; writing - review and editing, D.W. and Y.X.; project administration, D.W. All authors have read and agreed to the published version of the manuscript.

Funding: This work was financially supported by the National Natural Science Foundation of China (No.31601560).

Institutional Review Board Statement: Not applicable.

Informed Consent Statement: Not applicable.

Data Availability Statement: Not applicable.

Conflicts of Interest: The authors declare no conflict of interest.

\section{References}

1. Brown, K.L. Chemistry and enzymology of vitamin B12. Chem. Rev. 2005, 105, 2075-2149. [CrossRef]

2. Giedyk, M.; Goliszewska, K.; Gryko, D. Vitamin B12 catalysed reactions. Chem. Soc. Rev. 2015, 44, 3391-3404. [CrossRef] [PubMed]

3. Padmanabhan, S.; Jost, M.; Drennan, C.; Elías-Arnanz, M. A new facet of vitamin B12: Gene regulation by cobalamin-based photoreceptors. Annu. Rev. Biochem. 2017, 86, 485-514. [CrossRef] [PubMed]

4. Bastet, L.; Dubé, A.; Massé, E.; Lafontaine, D. New insights into riboswitch regulation mechanisms. Mol. Microbiol. 2011, 80, 1148-1154. [CrossRef]

5. Shelton, A.N.; Seth, E.C.; Mok, K.C.; Han, A.W.; Jackson, S.N.; Haft, D.R.; Taga, M.E. Uneven distribution of cobamide biosynthesis and dependence in bacteria predicted by comparative genomics. ISME J. 2018, 13, 789-804. [CrossRef] [PubMed]

6. Li, H.B.; Chen, F. Determination of vitamin B12 in pharmaceutical preparations by a highly sensitive fluorimetric method. Fresen. J. Anal. Chem. 2000, 368, 836-838. [CrossRef]

7. Castilho, S.; Borrego, A.; Henriques, C.; Ribeiro, M.F.; Fernandes, A. Monitoring cobalt ions siting in BEA and FER zeolites by in-situ UV-Vis spectroscopy: A DRS study. Inorg. Chim. Acta 2017, 455, 568-574. [CrossRef]

8. Moreno, P.; Salvado, V. Determination of eight water- and fat-soluble vitamins in multi-vitamin pharmaceutical formulations by high-performance liquid chromatography. J. Chromatogr. A 2000, 870, 207-215. [CrossRef]

9. Li, H.B.; Chen, F.; Jiang, Y. Determination of vitamin B12 in multivitamin tablets and fermentation medium by high-performance liquid chromatography with fluorescence detection. J. Chromatogr. A 2000, 891, 243-247. [CrossRef]

10. Lambert, D.; Adjalla, C.; Felden, F.; Benhayoun, S.; Nicolas, J.P.; Guéant, J.L. Identification of vitamin B12 and analogues by high-performance capillary electrophoresis and comparison with high-performance liquid chromatography. J. Chromatogr. A 1992, 608, 311-315. [CrossRef]

11. Shokrollahi, A.; Ebrahimi, F. Supramolecular-based ultrasonic-assisted dispersion solidification liquid-liquid microextraction of copper and cobalt prior to their flame atomic absorption spectrometry determination. J. Aoac Int. 2017, 100, 1861-1868. [CrossRef]

12. Kumar, S.S.; Chouhan, R.S.; Thakur, M.S. Trends in analysis of vitamin B12. Anal. Biochem. 2010, 398, 139-149. [CrossRef]

13. Kou, Y.; Lu, J.; Jiang, X.; Tian, B.; Xue, Y.; Wang, M.; Tan, L. Electrochemical determination of vitamin B12 based on Cu ${ }^{2+}$-involved fenton-like reaction. Electroanalysis 2019, 31, 1-10. [CrossRef]

14. Kreft, G.L.; Braga, O.C.D.; Spinelli, A. Analytical electrochemistry of vitamin B12 on a bismuth-film electrode surface. Electrochim. Acta 2012, 83, 125-132. [CrossRef]

15. Parvin, M.H.; Azizi, E.; Arjomandi, J.; Lee, J.Y. Highly sensitive and selective electrochemical sensor for detection of vitamin B12 using an Au/PPy/FMNPs@TD-modified electrode. Sensor. Actuat. B Chem. 2018, 261, 335-344. [CrossRef]

16. Kuralay, F.; Vural, T.; Bayram, C.; Denkbas, E.B.; Abaci, S. Carbon nanotube-chitosan modified disposable pencil graphite electrode for vitamin B12 analysis. Colloid. Surface. B 2011, 87, 18-22. [CrossRef] [PubMed]

17. Yang, N.; Wan, Q.; Wang, X. Voltammetry of vitamin b12 on a thin self-assembled monolayer modified electrode. Electrochim. Acta 2005, 50, 2175-2180. [CrossRef]

18. Tomčik, P.; Banks, C.E.; Davies, T.J. A self-catalytic carbon paste electrode for the detection of vitamin B12. Anal. Chem. 2004, 76, 161-165. [CrossRef]

19. Pala, B.B.; Vural, T.; Kuralay, F.; Cirak, T.; Bolat, G.; Abaci, S.; Denkbas, E.B. Disposable pencil graphite electrode modified with peptide nanotubes for vitamin B12 analysis. Appl. Surf. Sci. 2014, 303, 37-45. [CrossRef] 
20. Pereira, D.F.; Santana, E.R.; Piovesan, J.V.; Spinelli, A. A novel electrochemical strategy for determination of vitamin B12 by Co(i/ii) redox pair monitoring with boron-doped diamond electrode. Diam. Relat. Mater. 2020, 105, 107793. [CrossRef]

21. Wang, Y.; Zhou, W.; Jia, R.; Yu, Y.; Zhang, B. Unveiling the activity origin of a copper-based electrocatalyst for selective nitrate reduction to ammonia. Angew. Chem. Int. Edit. 2020, 59, 5350-5354. [CrossRef] [PubMed]

22. Reyter, D.; Bélanger, D.; Roué, L. Study of the electroreduction of nitrate on copper in alkaline solution. Electrochim. Acta 2008, 53, 5977-5984. [CrossRef]

23. Badea, G.E. Electrocatalytic reduction of nitrate on copper electrode in alkaline solution. Electrochim. Acta 2009, 54, 996-1001. [CrossRef]

24. Pignatello, J.J.; Oliveros, E.; MacKay, A. Advanced oxidation processes for organic contaminant destruction based on the fenton reaction and related chemistry. Crit. Rev. Environ. Sci. Technol. 2006, 36, 1-84. [CrossRef]

25. Babuponnusami, A.; Muthukumar, K. A review on fenton and improvements to the fenton process for wastewater treatment. J. Environ. Chem. Eng. 2014, 2, 557-572. [CrossRef]

26. Hoigné, J. Inter-calibration of oh radical sources and water quality parameters. Water Sci. Technol. 1997, 35, 1-8. [CrossRef]

27. Cheng, I.F.; Xie, Y.; Gyan, I.O.; Nicholas, N.W. Highest measured anodic stability in aqueous solutions: Graphenic electrodes from the thermolyzed asphalt reaction. Rsc Adv. 2013, 3, 2379-2384. [CrossRef]

28. Cheng, I.F.; Xie, Y.; Gonzales, R.A.; Brejna, P.R.; Sundararajan, J.P.; Kengne, B.A.F.; Aston, D.E.; McIlroy, D.N.; Foutch, J.D.; Griffiths, P.R. Synthesis of graphene paper from pyrolyzed asphalt. Carbon 2011, 49, 2852-2861. [CrossRef]

29. Hamam, A.; Oukil, D.; Dib, A.; Hammache, H.; Makhloufi, L.; Saidani, B. Polypyrrole coated cellulosic substrate modified by copper oxide as electrode for nitrate electroreduction. Surf. Rev. Lett. 2015, 22, 1550065. [CrossRef]

30. Okbamichael, M.; Sanudo-Wilhelmy, S.A. A new method for the determination of vitamin B12 in seawater. Anal. Chim. Acta 2004, 517, 33-38. [CrossRef]

31. Lee, C.; Wei, X.; Kysar, J.W.; Hone, J. Measurement of the elastic properties and intrinsic strength of monolayer graphene. Science 2008, 321, 385-388. [CrossRef]

32. Balandin, A.A.; Ghosh, S.; Bao, W.; Calizo, I.; Teweldebrhan, D.; Miao, F.; Lau, C.N. Superior thermal conductivity of single-layer graphene. Nano Lett. 2008, 8, 902. [CrossRef]

33. Rao, C.N.R.; Sood, A.K.; Subrahmanyam, K.S.; Govindaraj, A. Graphene: The new two-dimensional nanomaterial. Angew. Chem. Int. Edit. 2010, 48, 7752-7777. [CrossRef] [PubMed]

34. Achary, L.S.K.; Nayak, P.S.; Barik, B.; Kumar, A.; Dash, P. Ultrasonic-assisted green synthesis of $\beta$-amino carbonyl compounds by copper oxide nanoparticles decorated phosphate functionalized graphene oxide via Mannich reaction. Catal. Today 2020, 348, 137-147. [CrossRef]

35. Collins, D.A.; Hogenkamp, H.P. Adionuclide Labeling of Vitamin B12 and Coenzymes Thereof. US Patent 5,739,313, 1998.

36. Davies, M.J. The oxidative environment and protein damage. Biochim. Biophys. Acta 2005, 1703, 93-109. [CrossRef]

37. Sante-Lhoutellier, V.; Aubry, L.; Gatellier, P. Effect of oxidation on in vitro digestibility of skeletal muscle myofibrillar proteins. J. Agr. Food Chem. 2007, 55, 5343-5348. [CrossRef] [PubMed]

38. Brillas, E.; Bastida, R.M.; Llosa, E.; Casado, J. Electrochemical destruction of aniline and 4-chloroaniline for wastewater treatment using a carbon-ptfe $\mathrm{O}_{2}$-fed cathode. J. Electrochem. Soc. 1995, 142, 1733-1741. [CrossRef]

39. Cheng, Y.; Ma, B.; Tan, C.P.; Lai, O.M.; Panpipat, W.; Cheong, L.Z.; Shen, C. Hierarchical macro-microporous zif-8 nanostructures as efficient nano-lipase carriers for rapid and direct electrochemical detection of nitrogenous diphenyl ether pesticides. Sensor. Actuat. B Chem. 2020, 321, 128477. [CrossRef]

40. Manivel, P.; Madasamy, K.; Suryanarayanan, V.; Nesakumar, N.; Kulandaisamy, A.J.; Kathiresan, M.; Parthiban, M.; Velayutham, D.; Lee, K.M. Cu(HBTC) (4,4'-bipy)·3DMF nanorods supported on platinum electrode as an electrochemical sensing platform for efficient vitamin B12 detection. J. Taiwan Inst. Chem. Eng. 2019, 96, 1-10. [CrossRef] 